\title{
Ketogenic Diet: An Early Option for Epilepsy Treatment, Instead of A Last Choice Only
}

\author{
Huei-Shyong Wang, Kuang-Lin Lin
}

\begin{abstract}
Ketogenic diet (KD) was usually tried as a last resort in the treatment of intractable epilepsy after failure of many antiepileptics and even epilepsy surgery. Glucose transporter-1 deficiency and pyruvate dehydrogenase deficiency must be treated with KD as the first choice because of inborn errors of glucose metabolism. Infantile spasms, tuberous sclerosis complex, Rett syndrome, Doose syndrome, Dravet syndrome, etc., appear to respond to KD, and it has been suggested by the international consensus statement to use KD early. We believe that all patients with epilepsy, except those with contraindicated situations such as pyruvate carboxylase deficiency, porphyria, $\beta$-oxidation defects, primary carnitine deficiency, etc., may try KD before trying other regimens. (Biomed J 2013;36:16-17)
\end{abstract}

\section{Key words: antiepileptics, epilepsy, intractable epilepsy, ketogenic diet}

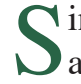
ince 1921, a ketogenic diet (KD) of low-carbohydrate, adequate-protein, and high-fat content has been used for the treatment of intractable childhood epilepsy by achieving the antiepileptic effects of fasting. ${ }^{[1]}$ Ancient records date back to the Middle Ages and even Biblical times when KD was achieved by fasting or as the so-called "water diet."[2] The KD was popular for treating epilepsy during the 1930s when few antiepileptics were available. After the discovery of phenytoin in 1938, many potent antiepileptics were found one after another and KD was abandoned gradually on account of its poor palatability and lack of placebo control studies primarily. It has been used continuously at several centers throughout the world in the USA and UK, but was not widely perceived as either effective or palatable for decades. Having resurged since 1994, KD was usually tried as a last resort in the treatment of intractable epilepsy after failure of many antiepileptics and even epilepsy surgery. Wang suggested that all patients should try KD before epilepsy surgery, including vagus nerve stimulation. ${ }^{[3]}$

\section{KD is no more too unpalatable}

The classic KD may contain $90 \%$ of daily calorie from fat that makes it unpalatable. Besides medium-chain triglyceride (MCT) KD as described by Liu and Wang in this issue, two less-restrictive KDs, the modified Atkins diet and low glycemic index treatment, have been developed recently. ${ }^{[4,5]}$ These diets allow the patients to have less fat and choose from a more liberal menu and enjoy the important eating quality of life in a long run. The modified Atkins diet particularly has no strict limitation in the protein amount that children with epilepsy may enjoy a steak or chicken feast with their families or friends sometimes. In our institute, patients try MCT KD in the first 3 months, and then freely shift to the other two alternatives as long as seizure reduction maintains. The poor-exchange children must stick to MCT KD, and some of them will rather drink MCT oil alone as liquid medicine and eat their food without MCT oil. Of course, MCT oil could be replaced by coconut oil, which is the purified source of MCT oil, in our experience. Since food is exchangeable everyday, even every meal, the palatable issue for classic KD is no more so difficult today. Also, KD should be used well in Asia, including Taiwan. ${ }^{[5]}$

\section{KD is no more lack of scientific evidence in efficacy}

Many neurologists and epileptologists did not recommend KD before because of lack of scientific evidence. Actually, it is difficult in conducting double-blind, place-

From the Division of Pediatric Neurology, Department of Pediatrics, Chang Gung Children's Hospital at Linkou, Chang Gung University College of Medicine, Taoyuan, Taiwan

Received: Oct. 14, 2011; Accepted: Dec. 7, 2011

Correspondence to: Dr. Huei-Shyong Wang, Division of Pediatric Neurology, Department of Pediatrics, Chang Gung Children's Hospital at Linkou. 5, Fusing St., Gueishan, Taoyuan 333, Taiwan (R.O.C.). Tel: 886-3-3281200 ext. 8200; Fax: 886-3-3288957;

E-mail: wanghs444@cgmh.org.tw

DOI: $10.4103 / 2319-4170.107155$ 
bo-controlled studies for KDs. However, this situation has changed. At least two articles of controlled studies about KD have been published recently: The first one was a randomized controlled trial that enrolled 145 children with intractable epilepsy and the second one was a blinded, crossover study of 20 children with Lennox-Gastaut syndrome. ${ }^{[6,7]}$ Both studies supported the efficacy of KD in the study group as compared to the control group.

\section{KD should be a first-line treatment not only for some specific metabolic disorders or epilepsy syndrome, but also...}

Inborn errors of metabolism such as glucose transporter-1 deficiency and pyruvate dehydrogenase deficiency must be treated with KD right after diagnosis of course. Infantile spasms (IS), tuberous sclerosis complex, Rett syndrome, myoclonic-astatic epilepsy (Doose syndrome), Dravet syndrome, etc., appear to respond very well to KD therapy as being reviewed by Kossoff and Wang. ${ }^{[5]}$

The evaluation and treatment of IS continues to be a significant challenge to clinicians. The Infantile Spasms Working Group, a working group committed to the diagnosis, treatment, and establishment of a continuum of care for patients with IS and their families, published a consensus of the US and mentioned about KD ${ }^{[8]}$ For IS specifically, younger children and those with fewer previously tried antiepileptics are more likely to have a response rate more than $90 \% .{ }^{[9]}$ Over the past 5 years at Johns Hopkins Hospital, Kossoff and his colleagues have offered the KD children with recent-onset IS as a first-line therapy instead of adrenocorticotropic hormone (ACTH) or vigabatrin. There was no statistical difference in spasm reduction rate between the $\mathrm{KD}$ and $\mathrm{ACTH}$ groups, and the spasm recurrence rate was lower in the KD group than in the ACTH group. ${ }^{[10]}$

The international consensus statement has provided us an optimal clinical management to a standardized KD treatment. ${ }^{[11]}$ Management guidelines for the general practitioner have been suggested too. ${ }^{[12]}$ For status epilepticus, there is also a good argument for using KD early, maybe not first, but after 2-3 days of failure in response to antiepileptics. ${ }^{[13]}$

Why should one wait for KD therapy until epilepsy fails to respond to antiepileptics and even surgery? Experience in the use of KD as early therapy in 13 patients has been reported to be similar to that in patients with intractable epilepsy. ${ }^{[14]}$ Ito and Oguni suggested that intractable childhood epilepsy should be treated with KD as an early option as well as a last resort. ${ }^{[15]}$ In our own opinion, KD treatment for epilepsy should be considered as the first, or at least early choice, and not the last resort only. The antiepileptic efficacy of KD is not lower than antiepileptic medicine if both of them are compared as a first-line therapy. Besides, KD is safe, and at least not worse than antiepileptics such as carbamaze- pine that causes Steven-Johnson syndrome in people with HLA-B*1502. ${ }^{[16]}$ We believe that many patients, except those with contraindicated situations such as pyruvate carboxylase deficiency, porphyria, $\beta$-oxidation defects, primary carnitine deficiency, etc. ${ }^{[5]}$ will decide to try KD before other regimens.

\section{REFERENCES}

1. Swink TD, Vining EPG, Freeman JM. The ketogenic diet: 1997. Adv Pediatr 1997;44:297-329.

2. Vamecq J, Vallée L, Lesage F, Gressens P, Stables JP. Antiepileptic popular ketogenic diet: Emerging twists in an ancient story. Prog Neurobiol 2005;75:1-28.

3. Wang HS. Is therapeutic trial with ketogenic diet and intravenous immunoglobulin mandatory before epilepsy surgery? Epilepsia 1995;36:S3:S240.

4. Liu YM, Wang HS. Medium-chain triglyceride ketogenic diet: An effective treatment for drug resistant epilepsy and a comparison with other ketogenic diets. Biomed J 2013;36:9-15.

5. Kossoff EH, Wang HS. Dietary therapies for epilepsy. Biomed J 2013;36:2-8.

6. Neal EG, Chaffe H, Schwartz RH, Lawson MS, Edwards N, Fitzsimmons G, et al. The ketogenic diet for the treatment of childhood epilepsy: A randomized controlled trial. Lancet Neurol 2008;7:500-6.

7. Freeman JM, Vining EP, Kossoff EH, Pyzik PL, Ye X, Goodman SN. A blinded, crossover study of the ketogenic diet. Epilepsia 2009;50:322-5.

8. Pellock JM, Hrachovy R, Shinnar S, Baram TZ, Bettis D, Dlugos DJ, et al. Infantile spasms: A U.S. consensus report. Epilepsia 2010;51:2175-89.

9. Hong AM, Hamdy RF, Turner Z, Kossoff EH. Infantile spasms treated with the ketogenic diet: Prospective single-center experience in 104 consecutive infants. Epilepsia 2010;51:1403-7.

10. Kossoff EH, Hedderick EF, Turner Z, Freeman JM. A case-control evaluation of the ketogenic diet versus ACTH for new-onset infantile spasms. Epilepsia 2008;49:1504-9.

11. Kossoff EH, Zupec-Kania BA, Amark PE, Ballaban-Gil KR, Bergqvist AC, Blackford R, et al.; Charlie Foundation, and the Practice Committee of the Child Neurology Society. Optimal clinical management of children receiving the ketogenic diet: Recommendations of the International Ketogenic Diet Study Group. Epilepsia 2009;50:304-17.

12. Lee PR, Kossoff EH. Dietary treatments for epilepsy: Management guidelines for the general practitioner. Epilepsy Behav 2011;21:115-21.

13. Kossoff EH. The fat is in the fire: Ketogenic diet for refractory status epilepticus. Epilepsy Curr 2011;11:88-9.

14. Rubenstein JE, Kossoff EH, Pyzik PL, Vining EP, McGrogan JR, Freeman JM. Experience in the use of the ketogenic diet as early therapy. J Child Neurol 2005;20:31-4.

15. Ito $\mathrm{S}$, Oguni H. Ketogenic diet for intractable childhood epilepsy; as an early option as well as a last resort. Brain Nerve 2011;63:393-400.

16. Chen P, Lin JJ, Lu CS, Ong CT, Hsieh PF, Yang CC, et al. Carbamazepine-induced toxic effects and HLA-B*1502 screening in Taiwan. N Engl J Med 2011;364:1126-33. 